\title{
Material concreto e tecnologias digitais: possibilidades para o ensino e a aprendizagem da Estatística
}

\author{
Camila Rubira Silva* \\ Suzi Samá**
}

\section{Resumo}

$\mathrm{Na}$ contemporaneidade, grande quantidade de informação contendo dados estatísticos é apresentada à populaçáo, demandando do leitor o conhecimento de conceitos básicos da Estatística para sua leitura e compreensão. Diante disso, evidenciamos a importância do estudo desta ciência desde a Educação Básica, uma vez que seu ensino possibilita ao estudante o desenvolvimento de habilidades e competências para o tratamento da informação. Assim, no presente artigo objetivamos apresentar um relato de experiência, à luz da teoria da biologia do conhecer proposta por Maturana e Varela (2005), realizado com base em observaçóes tecidas ao longo do planejamento e execução de duas oficinas delineadas para promover o ensino e a aprendizagem da Estatística. Essas oficinas foram desenvolvidas com estudantes do $7^{\circ}$ ano do ensino fundamental de uma escola da rede pública municipal da cidade do Rio Grande-RS. As atividades proporcionaram, por meio da construção de um espaço contextual e experimental, de material concreto e tecnologias digitais, o estudo de conceitos e procedimentos estatísticos.

Palavra-chave: Ensino fundamental; educação estatística; material concreto; tecnologias digitais.

\section{Concrete material and digital technologies: possibilities for the Statistics teaching and learning}

\footnotetext{
Abstract

In contemporaneity, a great amount of information containing statistical data is presented to the population, demanding from the reader the knowledge of basic Statistical concepts for their reading and comprehension. Therefore, we highlight the importance of the study of this science since Basic Education, since its teaching enables the student to develop skills and competences for understanding the information. Thus, in the present paper we aim to present an experience report, based on the Biology of Knowledge proposed by Maturana and

* Graduação em Matemática Licenciatura, mestranda do Programa de Pós-Graduação em Educação em Ciências: Universidade Federal do Rio Grande-FURG. E-mail: camilarubira@hotmail.com.

** Graduação em Matemática Licenciatura, mestrado em Engenharia Oceânica e doutorado em Educação em Ciências: Universidade Federal do Rio Grande-FURG. Professora do Programa de Pós-Graduaçấo em Educação em Ciências. E-mail: suzisama@furg.br.
} 
Varela (2005), produced from the observations made during the planning and execution of two workshops held to promote teaching and learning of the Statistics. These workshops were developed with students of the 7th grade of an Elementary School of the municipal public network schools of the city of Rio Grande-RS. These activities provided, through the construction of a contextual and experimental space of concrete material and digital technologies, the study of statistical concepts and procedures.

Keywords: Elementary school; statistical education; concrete material; technologies

\section{Introduçáo}

No presente artigo, apresentamos um relato de experiência realizado com base em observaçốes tecidas ao longo do planejamento e execução de duas oficinas delineadas para promover o ensino e a aprendizagem da Estatística a estudantes do ensino fundamental. Tal relato é amparado na teoria da biologia do conhecer (MATURANA; VARELA, 2005), a qual pressupóe um espaço do educar em que a aprendizagem aconteça no fluir das interaçóes, de modo que o estudante possa buscar o seu conhecimento no diálogo, aprendendo na convivência com o professor e com os colegas modos de viver. Maturana (1993) esclarece que "o espaço de convivência que proporcionemos vai determinar que modo de vida as crianças ou os educandos aprendem, e, portanto, que modo de convivência vão gerar eles próprios em sua vida" (p. 64).

Dessa forma, consideramos fundamental a criação de ambientes de aprendizagem, para o ensino da Estatística, que incentivem o estudante a construir o conhecimento de forma ativa e contextualizada. Pellanda (2009) corrobora ao destacar a importância da compreensão, por parte dos epistemólogos e educadores, da participação efetiva de cada ser humano na construção do seu conhecimento.

Com base neste entendimento, o Grupo de Pesquisa em Educação Estatística, da Universidade Federal do Rio Grande (FURG), ao qual este relato se vincula, busca promover ações e investigaçóes com vistas a potencializar o ensino da Estatística. Neste cenário, foram realizadas duas oficinas para estudantes do $7^{\circ}$ ano do ensino fundamental de uma escola da rede pública municipal de um bairro da periferia da cidade do Rio Grande-RS. Oficinas estas intituladas Dialogando com os Dados e Do Tratamento da Informação ao Consumo Consciente de Água. Tal proposta foi desenvolvida junto ao Programa Novos Talentos, da Coordenação de Aperfeiçoamento de 
Pessoal de Nível Superior (Capes). Esse programa visa disseminar o conhecimento científico através da promoção de atividades extracurriculares para estudantes da educação básica. Nesse sentido, planejamos e organizamos as oficinas de forma a proporcionar, a estes estudantes da educação básica, o ensino e a aprendizagem de conceitos e procedimentos estatísticos, por meio da criação de um espaço contextual e experimental de material concreto e tecnologias digitais.

Organizamos este artigo em seçôes: na primeira, discutimos a importância do ensino da Estatística desde a educação básica de modo a promover o letramento estatístico; na sequência, elaboramos um panorama acerca dos materiais concretos e das tecnologias digitais para o ensino da Estatística; em seguida, relatamos, à luz da teoria da biologia do conhecer, as observaçóes realizadas no planejamento e na execuçáo das oficinas delineadas para o ensino e a aprendizagem da Estatística, por meio da utilização de material concreto e das tecnologias digitais.

\section{Letramento estatístico: importância do ensino da Estatística desde a educação básica}

A apresentação de informações, por meio de conceitos como medidas estatísticas, tabelas e gráficos, é frequentemente utilizada para sistematizar aspectos relativos a diferentes campos do conhecimento, especialmente na mídia de massa. Para compreender tais conceitos e para que ocorra uma leitura interpretativa das informações divulgadas por meio de dados, são requeridos do cidadão conhecimentos básicos da Estatística.

Cazorla et al. (2008) acreditam que no mundo globalizado, ser letrado estatisticamente é fundamental para a convivência em sociedade. Definido por Gal (2002), o letramento estatístico consiste na habilidade do indivíduo interpretar, avaliar e comunicar criticamente as informaçóes estatísticas. Desse modo, para que um estudante desenvolva tal habilidade e possa

[...] abstrair reflexivamente todas essas informações veiculadas, em forma de gráficos e tabelas, é necessário que a escola traga para si a responsabilidade de introduzir e desenvolver o conhecimento estatístico com seus alunos, objetivando formar cidadáos capazes de ler, compreender e comparar dados estatísticos, bem como criticá-los. (CAZORLA et al., 2008, p. 2). 
Tal instrumentalização com conhecimentos estatísticos, segundo Lopes (1998, p. 15), “[...] possibilita ao estudante desenvolver a capacidade de coletar, organizar, interpretar e comparar dados para obter e fundamentar conclusôes, que é a grande base do desempenho de uma atitude científica". Além disso, o estudo desta ciência pode auxiliar o estudante na compreensão de informações e situaçóes apresentadas, em diferentes áreas do conhecimento, o que contribui na tomada de decisóes.

Diante da importância da Estatística na formação do cidadão, esta passa a figurar nos documentos oficiais da educação no Brasil no final da década de 1990. Nos anos de 1997 e 1998, os conceitos básicos de Estatística foram incorporados oficialmente na base curricular das escolas de ensino fundamental, com a publicação dos Parâmetros curriculares nacionais (PCN), anos iniciais e anos finais, respectivamente. Conforme as diretrizes desses documentos, os conceitos estatísticos são abordados no ensino fundamental na área da Matemática, mais especificamente no bloco "Tratamento da informação" (BRASIL, 1997; 1998). A abordagem de tais conceitos é justificada pela demanda social e pela constante utilização destes na sociedade. Assim,

[...] é importante salientar que a compreensão e a tomada de decisões diante de questôes políticas e sociais dependem da leitura crítica e interpretaçấo de informaçóes complexas, muitas vezes contraditórias, que incluem dados estatísticos e índices divulgados pelos meios de comunicaçấo. Ou seja, para exercer a cidadania é necessário saber calcular, medir, raciocinar, argumentar, tratar informaçôes estatisticamente etc. (BRASIL, 1998, p. 27).

A partir dos PCN, ganham espaço, no âmbito da educação básica, conceitos e procedimentos para que o estudante desenvolva habilidades e competências necessárias para seleção e interpretação crítica de tabelas e gráficos, compreensão e análise de argumentos e de fatos apresentados no cotidiano (BRASIL, 1998). O ensino desses conceitos possibilita ao professor abordar, na sala de aula, temas transversais apresentados através de técnicas estatísticas em jornais, revistas, internet, entre outros veículos de comunicação presentes no cotidiano dos estudantes. Segundo Lopes (2008, p. 2), é necessário desenvolver uma prática pedagógica "[...] em que os estudantes realizem atividades, as quais considerem seus contextos e possam observar e construir os eventos possíveis, por meio de experimentação concreta, de coleta e de organização de dados". 
Nesse sentido, na presente seção apresentamos a inserção do ensino da Estatística nos PCN e a necessidade do seu estudo a fim de promover o letramento estatístico dos estudantes. Na seção seguinte, elaboramos um panorama acerca dos materiais concretos e das tecnologias digitais no ensinar e no aprender Estatística.

\section{Material concreto e tecnologias digitais: possibilidades para o ensino e} a aprendizagem da Estatística

A abordagem de conceitos estatísticos, por meio do material concreto e das tecnologias digitais, pode potencializar os processos de ensinar e de aprender Estatística, caso considerem a participação efetiva do estudante no processo de construção do conhecimento. De acordo com Lopes (2008), é necessário - tanto com o auxílio de lápis e papel quanto das tecnologias digitais - que os estudantes desenvolvam habilidades usadas no processo de investigação estatística, para que sejam capazes de organizar dados, computar medidas estatísticas e escolher gráficos e/ou tabelas convenientes para sintetizar as informaçóes. Assim, consideramos importante que os estudantes compreendam a definição e o sentido dos conceitos ensinados para que consigam aplicá-los em situaçóes que exigiam o pensamento estatístico.

Lorenzato (2006) considera que a experimentação proporcionada pelo material concreto provoca no estudante o raciocínio, a reflexão e o desenvolvimento de questionamentos e estratégias para construção do seu conhecimento no seu próprio tempo. Desse modo, a aprendizagem de conceitos estatísticos vai depender da forma como o professor os emprega em sala de aula e da "[...] ação interiorizada dos alunos, pelo significado que dão às suas ações, às formulações que enunciam, às verificaçóes que realizam" (LORENZATO, 2006, p. 81).

Outra forma de potencializar os processos de ensinar e de aprender Estatística é inserir as tecnologias digitais no desenvolvimento das atividades pedagógicas. Tal inclusão pode favorecer a formação dos estudantes de modo a "[...] estarem atualizados em relação às novas tecnologias da informação e se instrumentalizarem para as demandas sociais presentes e futuras" (BRASIL, 1998, p. 96).

A familiarização e o uso didático das tecnologias digitais se revelam de suma importância, pois, apesar de estarem presentes no cotidiano de 
grande parte dos estudantes, muitas vezes, a utilização é apenas com fim recreativo. Samá, Araújo e Laurino (2011) ressaltam que as interaçôes com as tecnologias digitais alteram o nosso fazer e portanto os nossos processos de construção de conhecimento. De acordo com a teoria da biologia do conhecer, o aprender pode ser entendido como uma adaptação, pois o conhecimento dá-se pela interação entre a pessoa e o meio, o qual pode ser o professor, outros estudantes, o material concreto ou tecnologias digitais (MATURANA; VARELA, 2005).

Com base neste entendimento, as atividades das oficinas Dialogando com os Dados e Do Tratamento da Informação ao Consumo Consciente de Água foram planejadas e executadas de modo a criar um espaço contextual e experimental de material concreto e tecnologias digitais, evidenciando o potencial pedagógico destes recursos didáticos no ensinar e no aprender Estatística. Estes recursos foram inseridos nas oficinas a fim de contribuir para o desenvolvimento da reflexão, criatividade, autonomia e interação dos estudantes.

\section{Oficina Dialogando com os Dados}

A oficina Dialogando com os Dados teve uma primeira atividade na escola a fim de instigar a participaçáo dos estudantes de uma turma do $7^{\circ}$ ano do ensino fundamental. Dos 18 estudantes da turma, 12 participaram das demais atividades da oficina realizadas nos laboratórios do grupo de pesquisa na FURG, no contraturno (tarde) das aulas na escola, totalizando 20 horas. Nessa oficina abordamos conceitos como variáveis, tabelas e gráfico de setores. Inicialmente, questionamos os estudantes sobre o que entendiam por Estatística. Nessa oportunidade eles puderam refletir e discutir com os colegas suas compreensóes. Na sequência, propusemos uma pesquisa em jornais e revistas sobre as formas de apresentar e organizar dados, como tabelas e gráficos. Por fim, os estudantes vivenciaram os processos de uma pesquisa, desde a coleta, até a organização e a apresentação de dados. Para tal, utilizaram recursos computacionais, como planilha eletrônica, programa de apresentação de slides e sites da internet.

O trabalho com material concreto, nessa oficina, teve início com a pesquisa de reportagens, em jornais e revistas, que utilizaram gráficos e tabelas na divulgação da informação. Após esta investigação, os estudantes confeccionaram um cartaz (Figura 1), em cartolina, apresentando o que 
encontraram e elaborando interpretaçôes sobre as tabelas e os gráficos. $\mathrm{Na}$ realização desta atividade os estudantes puderam identificar diferentes formas de organizar e apresentar a informação, verificando também a dificuldade de sintetizar e comunicar tais informaçóes. Esta atividade mostrou aos estudantes as várias aplicaçôes da Estatística e as formas de sintetizar questôes referentes à economia, à política, ao esporte, à educação, à saúde, entre outras. Lopes (2008) acredita que trabalhando com essas questóes, que normalmente envolvem índices, tabelas, gráficos etc., "[...] podemos estar viabilizando a formação de cidadãos críticos, éticos e reflexivos” (p. 60). A abordagem de temas inseridos no cotidiano dos estudantes pode instigar produtivas discussóes, bem como despertar o interesse deles para o estudo.

Figura 1 - Pesquisa em revistas e jornais

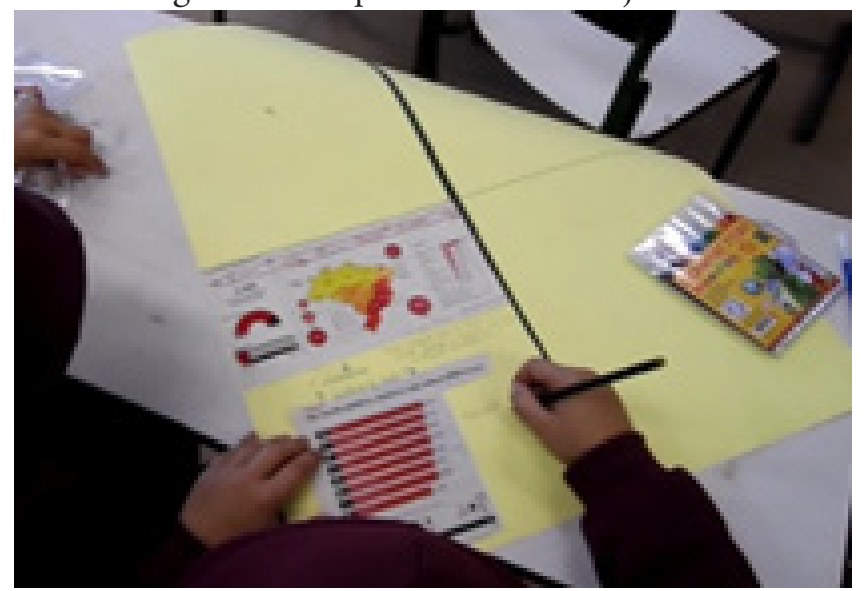

Fotografia: As autoras

Durante o trabalho com os gráficos e as tabelas, discutimos com os estudantes os diferentes modos de coletar os dados, e as formas de organizar e apresentar as informaçóes. A fim de explicar melhor os processos de uma pesquisa, levantamos, em sala de aula, dados a respeito das práticas corporais realizadas pelos estudantes. Esta atividade de coleta de dados entre os estudantes foi estimulada por Lopes (2008, p. 3), pois, segundo a autora, a construção de [...] gráficos e tabelas desvinculados de um contexto ou relacionados a situaçôes muito distantes do aluno pode estimular a elaboração de um pensamento, mas não garante o desenvolvimento de sua criticidade". 
Entre as práticas corporais realizadas pelos estudantes, surgiram as opçóes caçador, vôlei, futebol, caminhada, futsal e o mais votado handebol. Com os dados coletados, construímos uma tabela de frequência simples no quadro. Na sequência, reunidos em grupos e com o auxílio de alguns instrumentos, como régua, transferidor, compasso e calculadora, os estudantes construíram um gráfico de setores (Figura 2) para apresentação dos resultados da pesquisa. Inicialmente, o gráfico foi confeccionado em folhas de ofício, que serviram como molde, e posteriormente em espuma vinílica acetinada (EVA) colorida. Esse gráfico foi incluído no mesmo cartaz da atividade anterior. Os cartazes foram apresentados na aula de Matemática e fixados no mural da escola, com intuito de legitimar o trabalho desenvolvido pelos estudantes.

Figura 2 - Construção do gráfico de setores

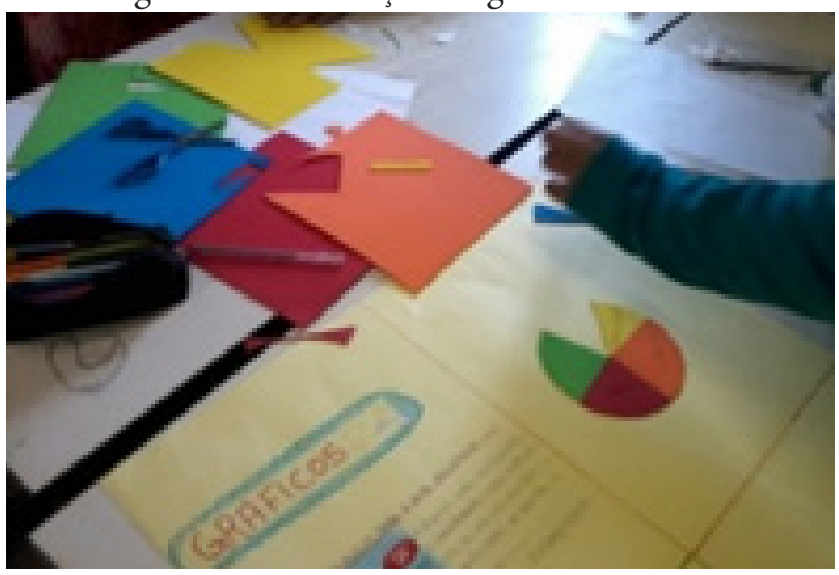

Fotografia: As autoras

Esse trabalho coletivo e experimental vai ao encontro do que defendem Maturana, Dávila e Muñoz (2008). Os autores consideram importante que os educandos vivenciem um espaço experimental, que gere possibilidades de autonomia na interação com os colegas. Espaços de convivência onde o educando possa se transformar em pessoa adulta, "como um ser que se respeita a si mesmo, que respeita os outros, que pode colaborar, que é autônomo, que é responsável” (MATURANA, DÁVILA, MUÑOZ, 2008, p. 120). 
No desenvolvimento desta oficina os estudantes ainda puderam se familiarizar, por meio da experimentaçâo das tecnologias digitais, com recursos como a planilha eletrônica, o programa de apresentação de slides e sites da internet. Para Kenski (2007) o computador, os sites educacionais, entre outras tecnologias digitais transformam a realidade da escola, dinamizam o espaço do ensinar e do aprender, tornando possível a conexão e aprendizagem coletiva dos estudantes. Assim, na sequência da oficina, os estudantes sintetizaram as informaçóes da pesquisa desenvolvida na sala de aula, sobre as práticas corporais, utilizando planilha eletrônica. Com base nessa planilha, eles construíram um gráfico de setores no computador.

Após, confeccionaram no programa de apresentação de slides, um cartaz digital (Figura 3) contendo o gráfico da pesquisa e figuras da internet que representassem os dados. $\mathrm{O}$ processo de experimentação do ambiente digital possibilitou uma maior autonomia dos estudantes na utilização dos recursos digitais disponíveis para construção dos cartazes. Segundo Pellanda (2009), os desafios enfrentados pelos estudantes, neste processo, exigem que eles se reorganizem de modo a responder às diferentes situaçóes que surgem.

Figura 3 - Pesquisa atividade física

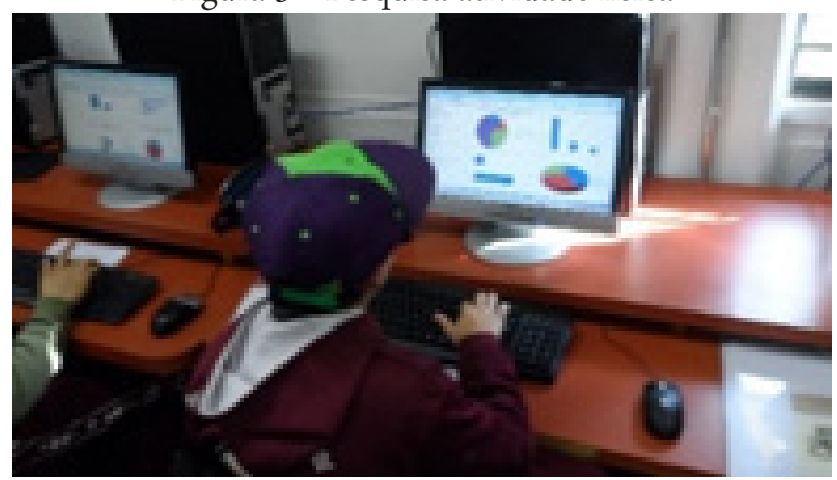

Fotografia: As autoras.

$\mathrm{Na}$ última atividade desta oficina, reunidos em grupos, os estudantes puderam realizar uma pesquisa vivenciando todo o processo de investigação, desde a escolha do tema, a definição da população, a construção do instrumento de coleta, a organização dos dados, até a apresentação e análise dos resultados. Planejamos esta atividade com base na pedagogia de Projetos de Aprendizagem proposta por Fagundes, Sato e Laurino-Maçada 
(1999). Com a utilização do computador, os estudantes puderam elaborar o instrumento de coleta de dados (questionário); organizar os resultados em uma planilha eletrônica; e produzir um cartaz digital no programa de apresentação de slides, com a síntese da pesquisa e imagens encontradas em sites da internet.

\section{Oficina Do Tratamento da Informaçáo ao Consumo Consciente de Água}

A elaboração desta segunda oficina surgiu a partir do interesse dos estudantes do ensino fundamental, que participaram da oficina anterior, em continuar trabalhando com os conceitos estatísticos. Dessa forma, as atividades da oficina foram desenvolvidas nos laboratórios do grupo de pesquisa na FURG, no contraturno (tarde) das aulas na escola, totalizando 20 horas. As atividades foram planejadas com base na sequência de ensino Planeta Água, proposta por Cazorla et al. (2011). Nessa oficina, apresentamos alguns procedimentos para tratar os dados presentes em uma conta de água, promovendo a discussão sobre conceitos estatísticos como medidas de tendência central, tabela e gráfico de linhas, bem como o consumo consciente de água.

Para familiarizar os estudantes com os conceitos, iniciamos perguntando o que entendiam por moda. Após algumas reflexóes, eles escreveram em uma folha o seu entendimento e discutiram com os colegas. O conceito de mediana foi abordado com a observação da altura de um grupo de estudantes em pé, enfileirados em ordem crescente, pelos demais alunos que debatiam sobre o que observavam com relação à altura dos colegas. Por fim, o conceito de média foi trabalhado a partir da apresentação de uma tabela contendo as idades dos membros de uma família. Com base nos dados divulgados nesta tabela os estudantes puderam interpretar e calcular a média das idades, debatendo com os colegas suas estratégias de cálculo. Vale aqui destacar, que a interação durante esta atividade foi de suma importância para compreensão dos conceitos.

Na prática pedagógica, aproveitar a vivência do aluno pode também se referir a aproveitar o conhecimento de um aluno para auxiliar outro, pois, às vezes, quando um não consegue fazer um exercício, resolver um problema, responder a uma pergunta, entender algo que o professor 
disse, basta uma palavra ou frase de um colega para que tudo se torne fácil. (LORENZATO, 2006, p. 25).

A constante interação entre os estudantes também foi observada durante o trabalho com os dados apresentados nas contas de água de suas casas. Para Maturana (2002), o próprio desenvolvimento individual, a formaçáo e o mundo de significados de cada ser dependem da interação social, no viver com os outros, de modo que os educandos aprendam a se respeitar e respeitar os outros.

Por meio da construção, interpretação e análise dos cálculos para verificação das medidas de tendência central dos dados referentes ao consumo de água, os estudantes discutiram as estratégias de cálculo e os resultados obtidos. Lorenzato (2006) esclarece que a experimentação do concreto, embora não seja suficiente para que aconteça a abstração matemática, é necessária para a aprendizagem inicial do conceito, neste caso, das medidas estatísticas.

Com este entendimento foi proposto à turma a construção coletiva de uma tabela em papel madeira (Figura 4), com os dados das contas de água. Além dos dados, os estudantes realizaram os cálculos das medidas de tendência central, como média, mediana e moda. Essa contextualização possibilitou refletir sobre o consumo consciente de água, as formas de desperdício e de como evitá-lo, viabilizando além da aplicação da Estatística no seu cotidiano, a discussão e conscientização de um tema tão importante na atualidade.

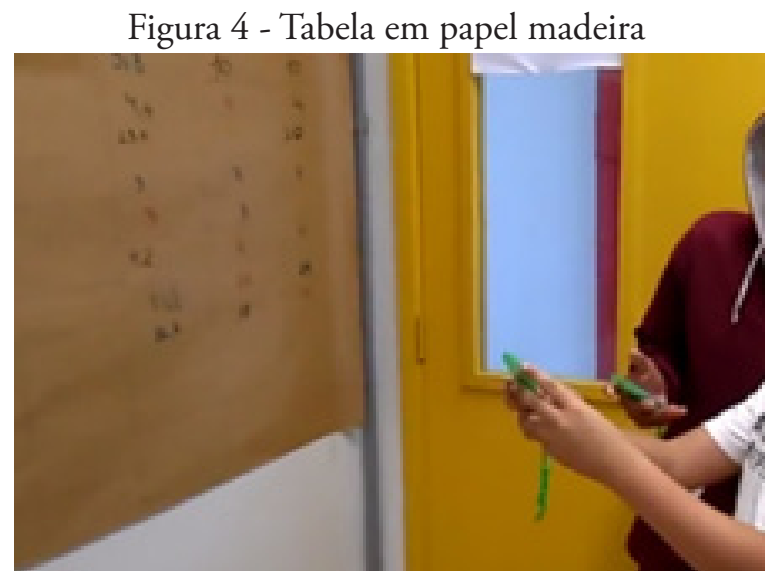

Fotografia: As autoras. 
Esta oficina ainda contou com uma atividade em que os estudantes puderam construir, interpretar e analisar a representação gráfica. Por meio de régua, papel quadriculado, transparência e caneta para retroprojetor, construíram um gráfico de linhas representando o consumo de água de sua casa, com base nos dados obtidos na conta de água. A confecçáo com esse material, transparência, permitiu a sobreposição de um gráfico ao outro, possibilitando aos estudantes a observação e análise do comportamento do consumo de água da sua conta e dos demais colegas. Para que esta comparação e análise pudessem ser realizadas, debatemos com os estudantes o conceito de escala apresentado nos gráficos.

Além do trabalho com material concreto, os estudantes puderam experienciar as tecnologias digitais. Para Kenski (2007) o que define a qualidade na educação é a interação promovida pela articulação entre a tecnologia, o desejo do estudante em aprender, a busca do professor por caminhos que levem a aprendizagem e os conhecimentos.

$\mathrm{Na}$ continuidade do trabalho anterior, no laboratório de informática, os estudantes realizaram pesquisas na internet, buscando curiosidades e reportagens a respeito das formas de desperdício de água e de como evitá-lo, confeccionando um portfólio coletivo. Cada estudante confeccionou um cartaz digital (Figura 5) no programa de apresentaçáo de slides, com a síntese de sua pesquisa e figuras ilustrativas.

Figura 5 - Cartaz digital

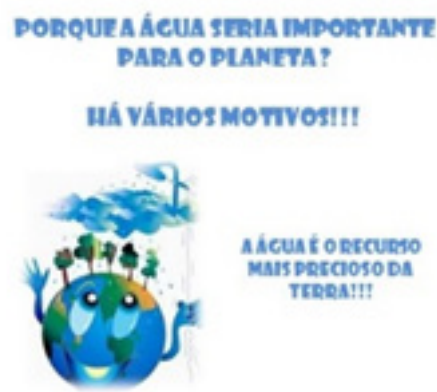

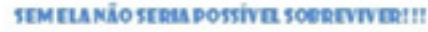

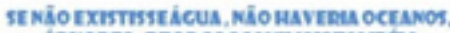

ARVOREs, E Todos os ANDMAs TAMEbM

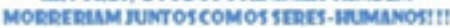

Fotografia: As autoras. 
Para Maturana (2002, p. 149), o trabalho no espaço digital "valida a dignidade do estudante ao não exigir pré-requisitos e aceitar qualquer ponto de partida legítimo para qualquer estudo". Por esse motivo, deixamos os estudantes livres tanto no processo de pesquisa quanto na escolha e organização do cartaz. Nesse momento, nosso papel foi auxiliar os estudantes na utilização da tecnologia e na superação das dificuldades encontradas por eles na realização da atividade.

As informaçôes apresentadas nas contas de água das casas dos estudantes também foram trabalhadas por meio das tecnologias digitais. Em planilha eletrônica eles computaram os dados sobre o consumo de água de cada residência, verificando a potencialidade de tal recurso tecnológico na organização e análise dos dados. Cazorla e Santana (2010) acreditam que o trabalho manual com dados muito grandes, por vezes, leva o estudante a gastar tanto tempo para interpretar, analisar e discutir os resultados que "[...] a parte mais nobre da Estatística, aquela que se relaciona com a atividade cognitiva do aluno, fica em segundo plano, ou mesmo corre o risco de não acontecer" (p. 145).

Após organizar os dados da sua conta na planilha eletrônica, os estudantes construíram um gráfico de linhas que os representasse, interpretando e analisando o consumo de água de sua família. Com este gráfico feito no computador, os estudantes puderam comparar com os gráficos inicialmente construídos, em transparências, de forma manual (Figura 6).

Figura 6 - Gráfico de linhas do consumo de água de cada família

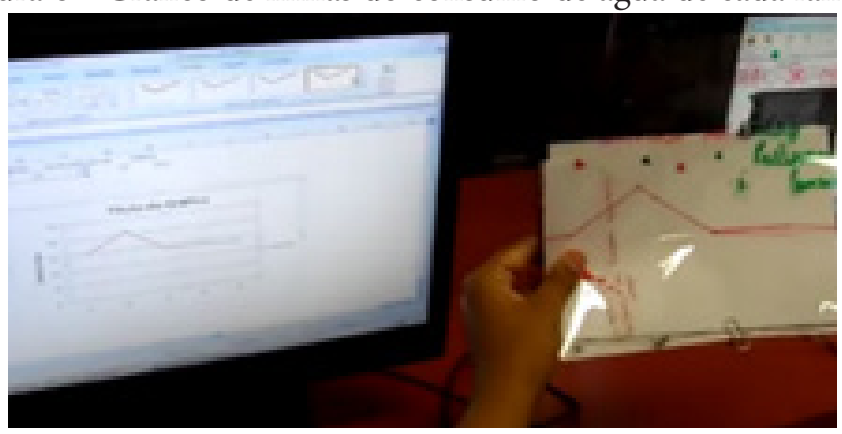

Fotografia: As autoras.

Na sequência, por meio da construção de um cartaz digital, contendo um único gráfico de linhas múltiplas que representasse o consumo de 
água das famílias dos colegas, os estudantes puderam analisar e apresentar suas interpretaçôes (Figura 7), verificando quais famílias tinham o maior ou menor consumo e quais os possíveis motivos para tal resultado, discutindo estratégias para a economia de água.

Figura 7 - Gráfico de linhas múltiplas do consumo de água de cada família

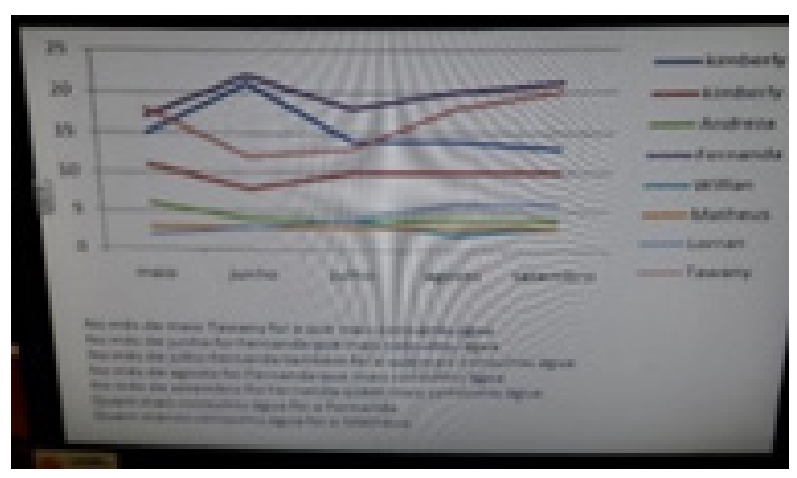

Fotografia: As autoras.

\section{Consideraçóes finais}

As oficinas apresentadas neste trabalho visaram a promover a criação de um espaço contextual e experimental, de material concreto e tecnologias digitais, para o ensinar e o aprender Estatística. Nas atividades planejadas e desenvolvidas procuramos superar o ensino de conceitos estatísticos, muitas vezes, desvinculado da realidade do educando.

Com base nas concepçóes de educaçáo propostas por Maturana e Varela (2005), defendemos o desenvolvimento de propostas pedagógicas que valorizem as vivências dos estudantes e integrem a utilização de material concreto e tecnologias digitais, de forma a potencializar o processo de ensino e de aprendizagem da Estatística. O planejamento de atividades como as aqui relatadas, que consideram a participação contextualizada e ativa do estudante, além de despertar o interesse dele para o estudo, dinamizam o trabalho em sala de aula promovendo uma aprendizagem ativa e autônoma. Com isso, buscamos proporcionar, através da interação entre os educandos, os professores, os colegas, o material concreto e as tecnologias digitais, um 
espaço de convivência que estimulasse o desenvolvimento do letramento estatístico necessário para o convívio social do estudante.

\section{Referências}

BRASIL. Ministério da Educação. Secretaria de Ensino Fundamental. Parâmetros curriculares nacionais: anos iniciais do ensino fundamental $\left(1^{\circ} \mathrm{e}\right.$ $2^{\circ}$ ciclos Matemática). Brasília: MEC/ SEF, 1997.

BRASIL. Ministério da Educação. Secretaria de Ensino Fundamental. Parâmetros curriculares nacionais: anos finais do ensino fundamental $\left(3^{\circ}\right.$ e $4^{\circ}$ série Matemática). Brasília: MEC/ SEF, 1998.

CAZORLA, I.; PAGAN, A.; LEITE, A. P.; MAGINA, S. A leitura e a interpretação de gráficos e tabelas no ensino fundamental e médio. In: SIMPÓSIO INTERNACIONAL DE PESQUISA EM EDUCAÇÁO MATEMÁTICA, 2, 2008, Recife. Anais... Recife: UFRP, 2008. (não paginado). Disponível em: <http:/www.lematec.net.br/CDS/SIPEMAT08/ artigos/CO-76.pdf>. Acesso em: 22 fev. 2018.

CAZORLA, I.; KATAOKA, V.; SANTANA, E. CASADEMUNT, M. Planeta água. Ed. Itabuna: Via Litterarum, 2011.

CAZORLA, I.; SANTANA, E. (Org.). Do tratamento da informação ao letramento estatístico. 1. ed. Itabuna: Via Litterarum, 2010.

FAGUNDES, L; SATO, L.; LAURINO-MAÇADA, D. Aprendizes do futuro: as inovaçóes começaram! Brasília: Secretaria da Educação a Distância, Ministério da Educação, 1999.

GAL, I. Adults' statistical literacy: Meanings, Componentes, Responsabilities. In: International Statistical Review, n. 70, p. 1-25, 2002.

KENSKI, V. M.; Educação e tecnologias: o novo ritmo da informação. 2. ed. Campinas: Papirus, 2007.

LOPES, C. A. A probabilidade e a estatística no ensino fundamental: uma análise curricular. 1998. 127f. Dissertação (Mestrado em Educação) Faculdade de Educação, Universidade Estadual de Campinas, Campinas, SP, 1998. 
LOPES, C. A. O ensino da estatística e da probabilidade na educação básica e a formação dos professores. Caderno Cedes, Campinas, SP, v. 28, n. 74, p. 57-73, 2008.

LORENZATO, S. (Org.). O laboratório de ensino de matemática na formação de professores. Campinas: Autores Associados, 2006.

MATURANA, H. As bases biológicas do aprendizado. Dois Pontos, Belo Horizonte, MG, v. 2, n. 16, p. 64-70, 1993.

MATURANA, H. Emoçôes e linguagem na educação e na politica. Tradução de José F. C. Fortes. Belo Horizonte: Ed. UFMG, 2002.

MATURANA, H. Transformación en la convivencia. 2. ed. Santiago: Dolmen, 2002.

MATURANA, H.; DÁVILA, X.; MUÑOZ, I. Os fundamentos biológicos do educador e do educador social. In: VIANNA, B. (Org.). Biologia da libertação: ciência, diversidade e responsabilidade. Belo Horizonte: Mazza, 2008. p. 114-123.

MATURANA, H.; VARELA, F. A árvore do conhecimento: as bases biológicas da compreensão humana. 5. ed. São Paulo: Palas Athena, 2005.

PELLANDA, N. M. C. Maturana e a educação. Belo Horizonte: Autentica Editora, 2009.

SAMÁ, S. P; ARAÚJO, M. S.; LAURINO, D. P. A educação a partir da biologia do conhecer na sociedade da informação e comunicação. In: SEMINÁRIO INTERNACIONAL DE EDUCAÇÃO EM CIÊNCIAS, 2011, Rio Grande. Anais... Rio Grande, RS: SINTEC, 2011. p. 813-823.

Recebido em: 7 abr. 2017.

Aceito em: 3 jul. 2017. 